\title{
Automation of Batch Production in Paint Industry using PLC
}

\author{
L.Chitra, Siranjeevi .S, Manikandan .A, Saravanan .G
}

\begin{abstract}
This paper presents the development of automatic control over batch type production in the paint industry. The automation technique for the manufacturing of paint industry is applied wit0068 the help of programmable Logic Controller. In this task, the analytical compute model for optimizing the functions of the volume processing plant is capable of handling all possible decision variables in the setup. The synthesized function is used in a dominant paint construct plant. This workconcentrate plant is a multi-product, batch processing plant, with a ample variety of products, challenge for various process apparatus at the manufacturing site. The plant under consideration working in accordance with the principle of "order-based" production. Therefore, this application can be classified as a short-term organize of a real case multi-product module alter plant.

Keywords : Automation, Batch Production, PLC, Paint industry.
\end{abstract}

\section{INTRODUCTION}

Paint is the combination product of different chemicals at different ratios. The manufacturing done in paint industries has the following steps-

- storing chemicals in the tank form area (main storage),

- transferring chemicals to process storage tank,

- batch production area,

- packing area.

This work in the process industry production area is automated. A programmable logic composed is an industrial digital computer that reliably controls the process. The overall process is checked and composed with the help of Programmable Logic Controller. The overall automation process is clearly shown in SCADA Screen. The powerful challenges faced in the batching system is clearly defined and digitalized to meet the challenges. Thus the recipe is followed uniformly in the automation process and the production process is flexible and follows the safety standards. The consistent quality of the reproducible batching system makes the automatic system a successful system. The integration of new concepts increases the transparency in the recording system of automation [1]. The report is generated with all the data available in the system

Revised Manuscript Received on December 16, 2019

L. Chitra*, Associate Professor and Head, Department of EEE, Aarupadai Veedu Institute of Technology, Chennai, India

Siranjeevi S, Department of EEE, Aarupadai Veedu Institute of Technology, Chennai, India.

Manikandan A, Department of EEE, Aarupadai Veedu Institute of Technology, Chennai, India.

Saravanan G, Department of EEE, Aarupadai Veedu Institute of Technology, Chennai, India. whenever required and also maintains the quality. The changes in the batch process can be comprehended easily. The optimum process control and the production which is designed flexible makes the best automatic batching system. Thus the paint industry permits us to react rapidly to changes in the market conditions and the specified dynamic environment .

The increased utilization of production plants along with improved. Production flexibility causes the reduction in market time and also reduces the overall operating and lifecycle costs.

\section{PLC PANEL}

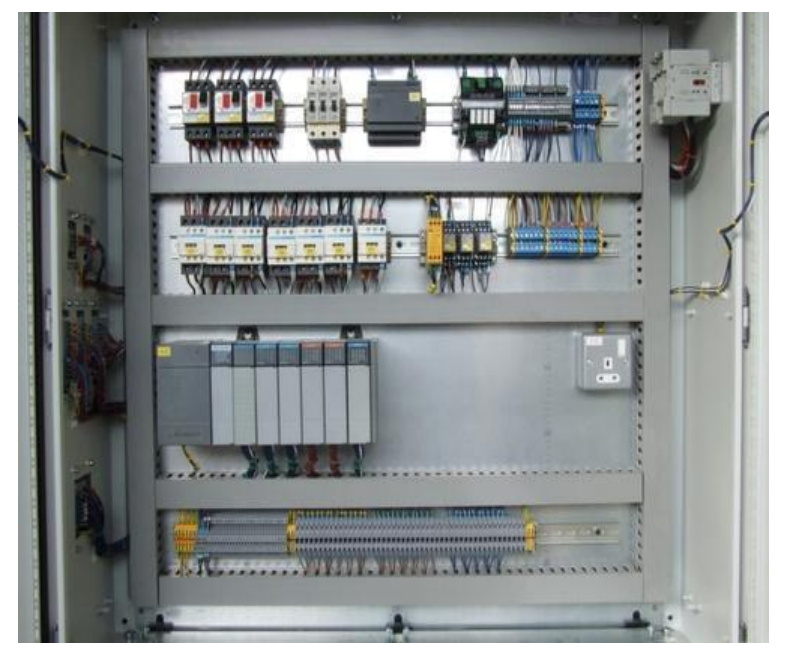

Fig. 1. PLC panel

Programmable Logic Controller (PLC) is a control group, otherwise familiar as the PLC computerization Panel [2] PLC is considered one of the most essential and efficient restraint panels. PLC is mainly used in many electronic and electrical circuit furniture. Fig. 2 shows the panel of PLC. The power consumption is very low and it is highly capable of giving higher output. The size of the system is also very small. The integration of stable PLC logic and immaculate PLC hardware programming was done. PLC is more advantageous when compared to the conventional type of controllers .some of the advantages are modification of logic is easy, size of the controller is small. Advanced technology and remote communications between devices have built PLC computerization restrains panels an edge in all applications related to conventional relay systems.

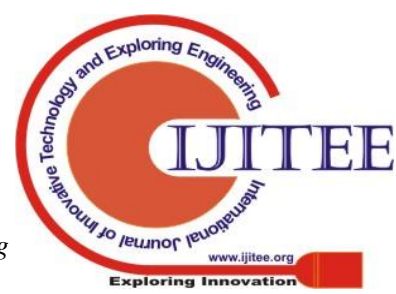




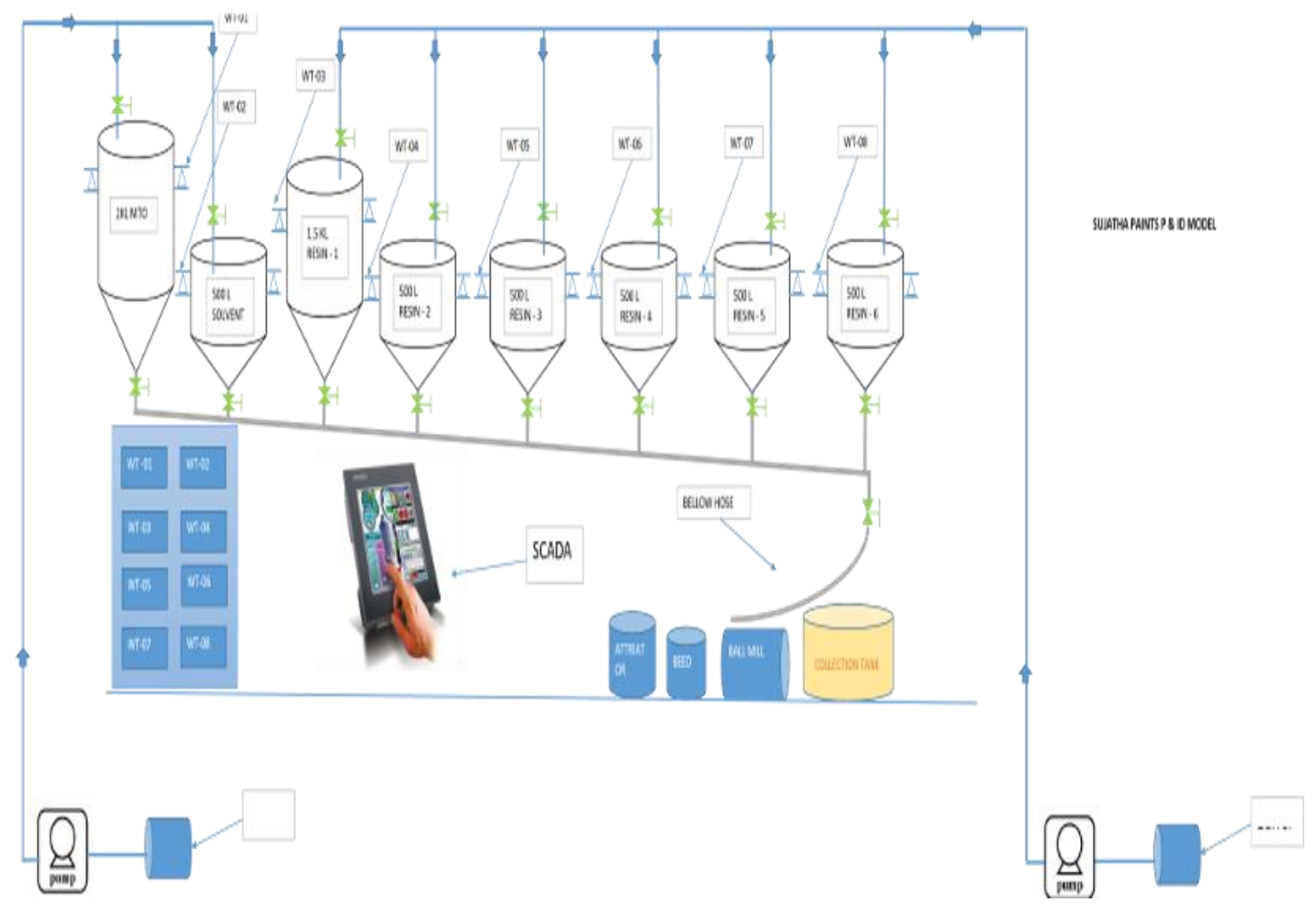

Fig. 2.Layout of piping and instrumentation diagram of paint industry

Control Systems Engineers has supplied PLC-based panels from Alan Bradley, Siemens, Modigon, GE Banook [3]. Controllers range from low input output application to complex input, output systems, provided by engineers. Control Systems Engineers have created a variety of protocols for remote communication of PLC panels. Provides various messages and restrains of the process plant to the HMI / MMI operator through PLC based panels, touch screen MMI. This makes the system a very effective control system. The team is designed based on IP evaluation. IP or threshold security ratings are defined in International Standard EN 60529 (British BS EN 60529: 1992, European IEC 60509: 1989). Fig.2.3 shows the security of the entry of the electronic device. They are used to define the sealing efficiency of foreign bodies (tools, dirt, etc.) and electrical connections against moisture penetration.

Main components in plc panel are [4]

- Terminal fuse blocks-fused/normal

- $\quad$ MCB-miniature circuit breaker

- PLC

- Racks

- $\quad$ Arrangement diagram

- Wiring diagram

- Indicating lights

- Ventilation fans
IP (Ingress Protection) Ratings Guide

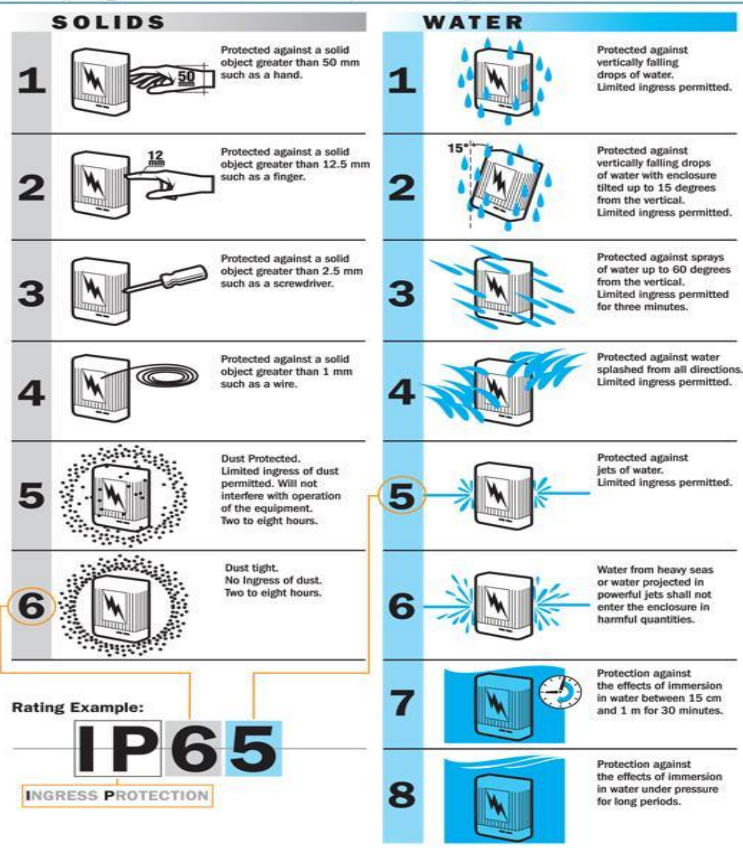

Fig. 3.Ingress Protection of electronic devices

The operation of an industry in fully automation mode is explained with PLC.PLC is the 
key which is widely using tool in an industries to control and read the entire process of the plant, while in running condition of the PLC ladder program the changes in the rungs are understandable by a skilled engineer only others can also understand the operation with some minimum efforts. SCADA system can also be implemented so that the changes in the operation and process are easily understandable to a Client [5]. The differentiation in color of the motor, valves, filling of liquid in pipes are visible to all so that less skilled operator can also easily control the plant. The required main components to operate the paint manufacturing -batch process plant in automation are control panel with PLC controller (Schneider M340), no. of I/O ports (based on requirement), computer with required software pumps, weight transmitters (load cell), two speed valves, three speed valves, etc.

\section{PLC-SCHNEIDER}

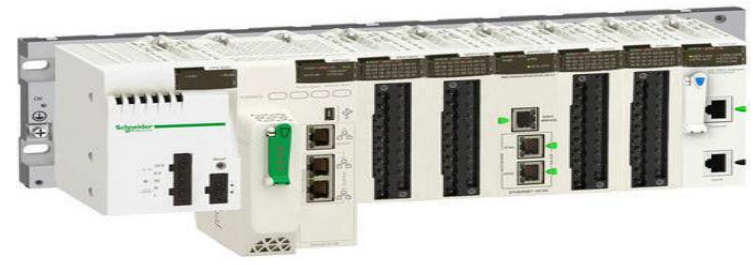

Fig. 4.M340 PLC

Modicon M340 PLC is used for this type of application [9]. It is a mid-range compact PLC. Fig.3.1 shows the image of the M340 PLC. The Modicon Program Computerized Controls (PAC) are configured to meet the needs of the process department and a wide range of demanding automation applications [6]. The Modicon M340 can be used separately, but is a perfect companion to the Modicon Premium and Modicon Quantum. This increases the efficiency, quality and profitability of the industrial process and the comfort of the machinery [10].It is a high performance processor with internal memory of $4 \mathrm{MB}$ designed to manage application upto $70 \mathrm{~K}$ instruction and $256 \mathrm{~KB}$ data. Application can be backed up in sd card and data in the internal flash memory.No battery is required.The plug and load technology of the card enables us to easily update the application and transfer to other machines with no disruption of operation.

\section{A. Specification of PLC used memory details}

- The additional file storage can be extended up to $128 \mathrm{MB}$ with FTP access.

- The application back-up is provided in the memory card

- The Programming code is given up to 70 Kinst.

\section{B. Specific applications}

- Library for Process control (Integrated Process Control library)

- No battery requirement

- The detailed integrated RTU solution for Water, O\&G, Power and Infrastructures are provided

- New analog I/O modules (High density)

- Counting PTO module

- SD card technology for protection of SI and OEM's

- The extended temperature range $\left(-25^{\circ} \mathrm{C}+70^{\circ} \mathrm{C}\right)$

\section{PRODUCT DESCRIPTION}

\section{A. List of components}

The following are the components in batch production and its control:

- Pumps

- Solenoid valves

- Weight transmitter (I 400)

- Normal valves

- 2 speed valves

- Storage tanks

- Paint collecting barrels

- Control panel with PLC

- Computer with required software

\section{B. Two speed valves}

The two speed faucet are in a small able set, execute and it is mainly controlled by the help of the solenoid, which is built to move from full speed to slow speed in restrain motion by coiling. Also known as Quick Advance and bolster Valves, the execute two-speed valves are pre-designed hydro mechanical packages that are integrated to control flow. The solenoid valves in a valve assembly allow for multiple speeds to operate. Applying proper control over packages, many hydraulic systems control the speed at which equipment is required to work. Line-fitted valves are available or have six different circuits ISO modules: meter in B, meter out D, meter out A or B, meter in A or B. Two-actuator actuators -Speed piping can work fast or slow using the initially open or normally closed solenoid valve commonly.

The benefits and the important features are given as following:

- The Compensated or non-compensated flow controls are present in the system.

- It is rated nominally with a value of 15 to 120 GPM and up to 5000 PSI.

- It is Compact and cost effective solution to multi-speed applications.

- Vuitton seals are available as a non-standard option upon request.

- Uses interfaces with a standard of D03-D10 valve .

\section{Solenoid valves}

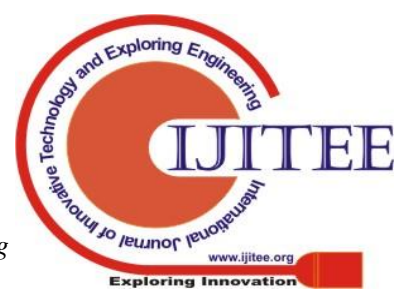




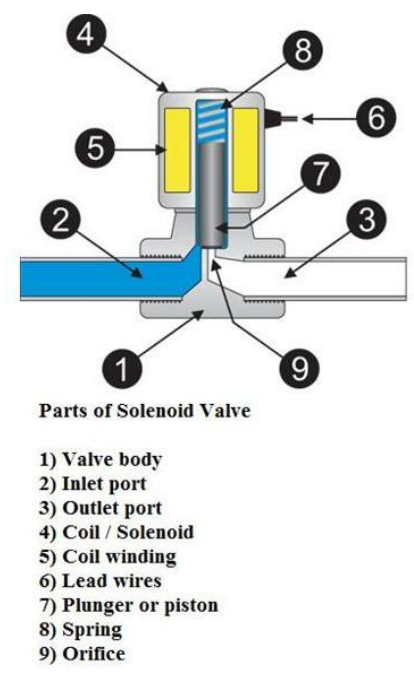

Fig. 5.Solenoid Valve

Fig.5 shows the parts of the solenoid valve.Fig. 6 shows the detailed working of Solenoid valve. The sensors are placed in the outlet side of the solenoid valve to control the current for the valve. The value of the fluid flow is realized and this allows the current to flow through the solenoid valve. The energetic valve receives magnetic energy, which is created to induce the action of the plunger against the action of the spring. This movement of the plunger in the upward direction allows the opening of the loop to increase the rate of flow. Thus the flow of flowing in this moment flows from the input port to the output port. . If the needed flow of fluid is low, the sensor accepts low current to be sent to the solid valve. The constant flow rate is maintained by transmitting static current to the solenoid valve. Therefore the place of the plunger and the opening of the rotor is stable. When sensor flow is no longer needed in this process, it completely stops the flow of current to the solenoid valve. Because of this, the solenoid valve receives de-energization and reaches the bottom of the plunger and completely closes the loop, thus stopping the flow of fluid from the inlet port to the outlet port.

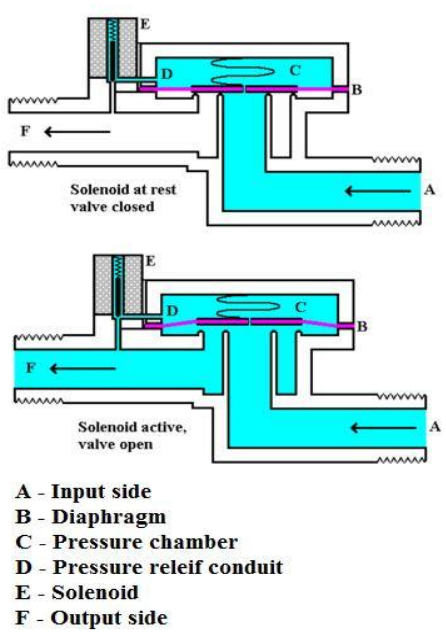

Fig. 6. Working principle of solenoid valve

Thus the valve operates as per the requirement of the flow required. When a certain amount of flow is needed, it opens the valve sufficiently and when no flow is needed, it completely closes the valve.

\section{400 weight transmitter}

The I 400 systems provides an upgradeable and new solution to the different problems that can arise with integration of weighing into the industrial process. The important three elements structured around a CAN Open field bus is given by the Graphic Terminal, the weight transmitter(s) and field bus coupler.

\section{VIJEOCITECT SCADA SOFTWARE}

SCADA systems are almost simple, that is used to monitor the working conditions of a small office building, or is incredibly complex, its also used in power plant and water corporation [7]. In our paint automation batch process, we are monitoring and controlling the entire process of the plant in a single control room. The changes happening in the plant can be visualized in the SCADA screen, i.e. whether the motor is Running, in Stop position and Trip conditions and it can be controlled by soft buttons.

\section{PRO-SOFTWARE}

Unity pro software creates the interfacing platform between the user and PLC in computer. By using this software we can instruct or program the PLC how to work. This software is special for Schneider PLC and it is compatible for all range of Schneider PLC. IP address is used to control the PLC and connect many PLC to one system or many systems to one PLC [8].

\section{PROPOSED SYSTEM}

The control of the total process with PLC is done by instructing the PLC in unity pro software. The following steps are to be done to follow the instruction. The configuration is a process to make the software understand the type and model of PLC and its modules .The analog I/O modules, Digital I/O modules, NOE modules, additional racks are included. All the model numbers are specified in the hardware. We have to select the model in the predefined model data in unity pro after configuring the devices, the network connection should be established between PLC and system. There are three types of communication port. The first one is USB which is used to load the program .The next one is the Ethernet TCP/IP which can be used to load the program, configure, send and receive data to and from PLC. The third one is the Serial communication is used to collect the information from PLC to system.

\section{A. Programming for batch process}

The list of programming is

- Structured text

- Flow chart

- Ladder diagram

- Functional block diagram 
The input and output module are connected to input and output pin to the controller respectively. The program should be done in the programming device. After writing the program, it is executed, build the project and transfer the program to PLC. Finally, run button is pressed to start the execution of the program

\section{B. Control block diagram}

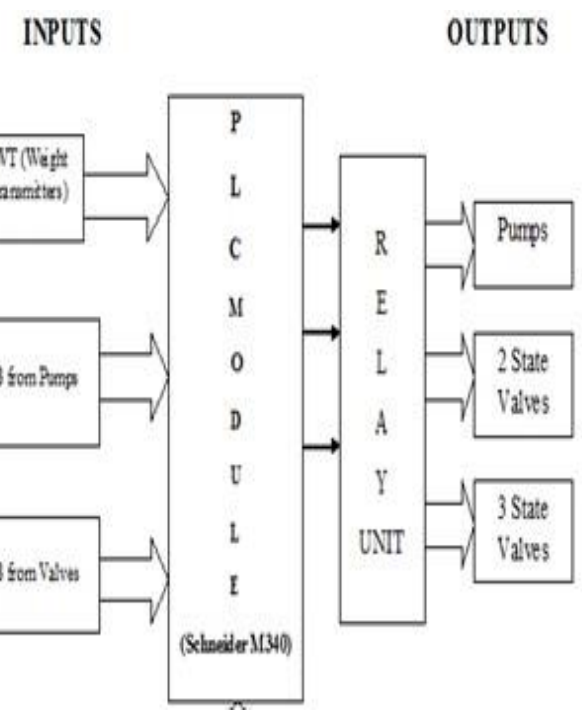

Fig. 7.Block diagram of PLC process

Fig.7 shows the block diagram of PLC process which explains the input and output devices connected to the input module and output module respectively.

\section{RESULTS}

\section{A. PLC programming - ladder logic}

The Ladder logic explains the connection of input and output devices with the necessary logic for the control and monitoring of various process variables. The opening and closing of the valves are controlled with the timer instructions. Fig (8-11) shows the PLC programming ladder logic.

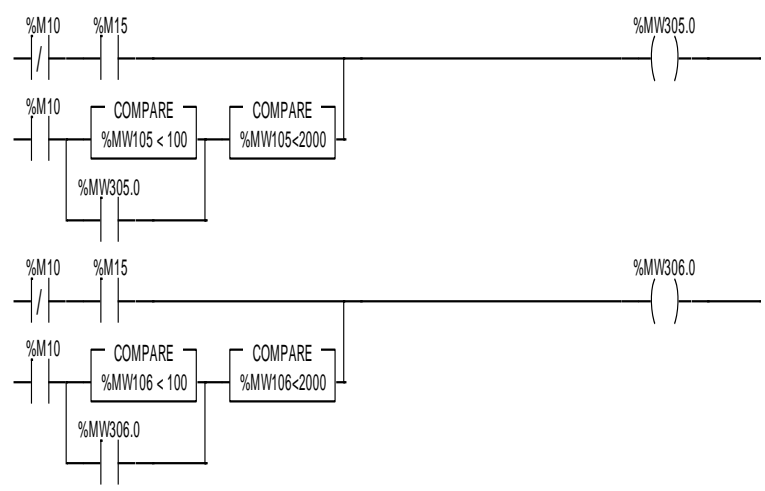

Fig. 8. Block diagram of PLC programming ladder logic

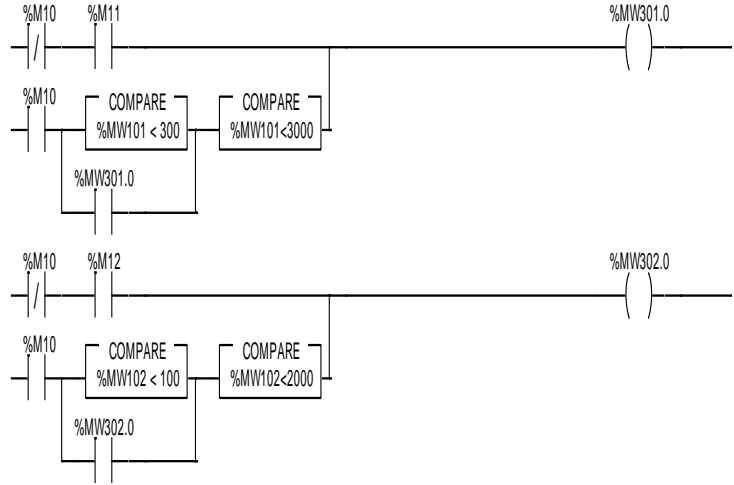

Fig. 9.Block diagram of PLC programming ladder logic

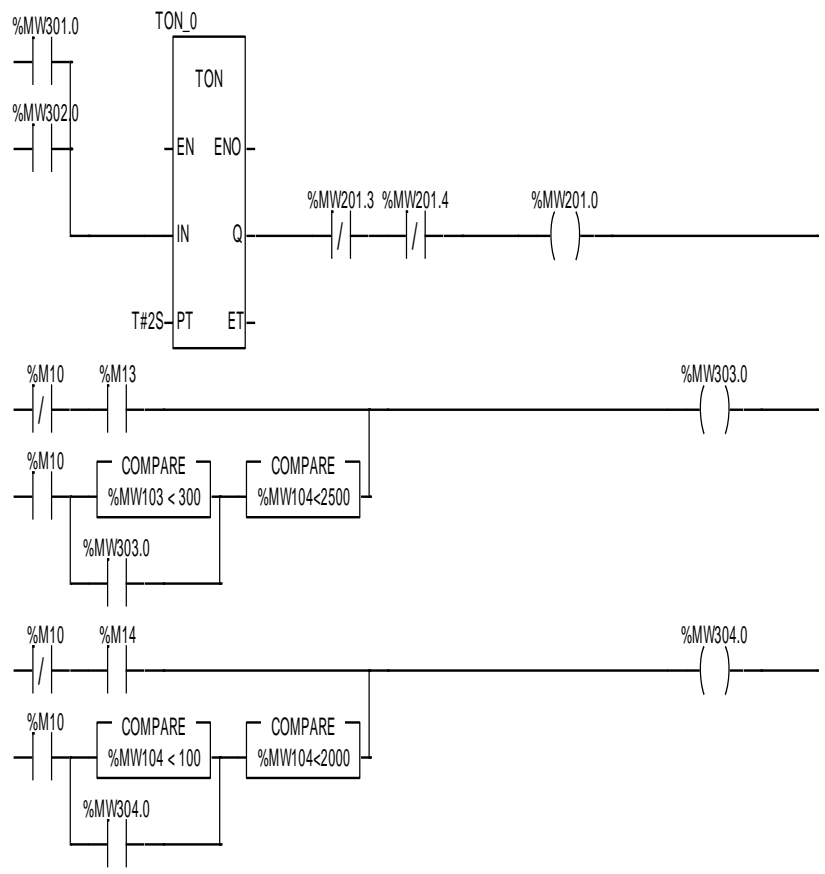

Fig. 10. Block diagram of PLC programming ladder logic

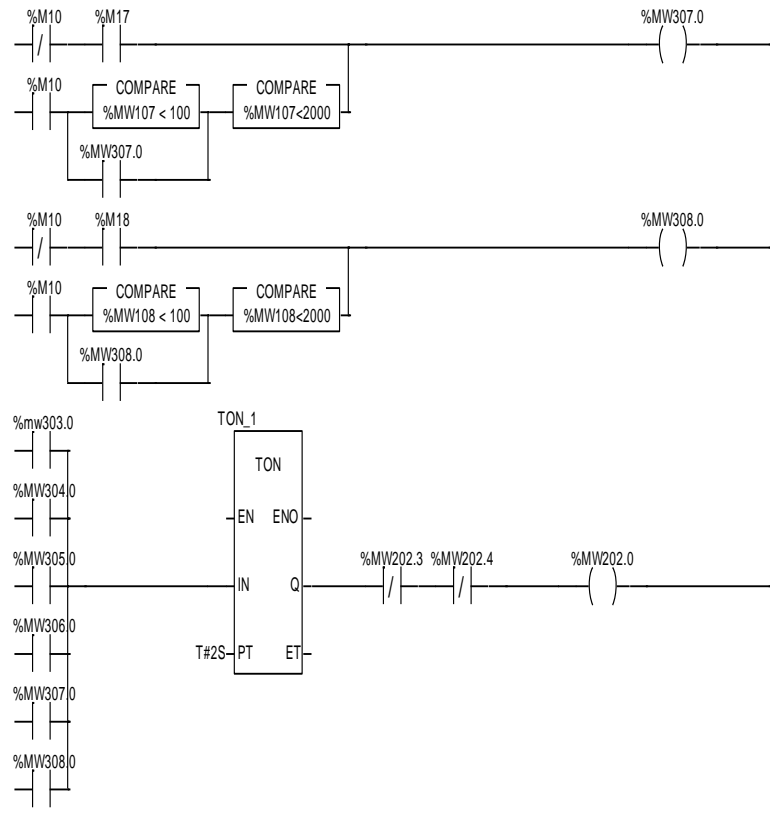

Fig. 11. Block diagram of PLC programming ladder logic 


\section{CONCLUSION}

The important aspect of paint industry is producing a combination of different chemicals which is the main function and it is controlled by using PLC and SCADA. This method relies on varied objectives like superior quality, increased efficiency, high profit and others depending upon the purpose of the company that implies in it. This project is implemented in a paint industry to produce different recipes of chemical products (paints). The Automation of the process operated using PLC ladder program is user friendly, but the running process can be viewed by clients and operator in graphical screen using SCADA software. This screen developed explains is used the plant process and the system easily troubleshoot the problem the graphical screen is used to rectify the problems without going to the corresponding floor. The automation process also has a backup of all process in storage devices

\section{REFERENCES}

1. Rahul Pawar, Dr. N. R. Bhasme, “Application of PLC's for Automation of Processes in Industries “, Int. Journal of Engineering Research and Applications, ISSN: 2248-9622, Vol. 6, Issue 6, (Part - 3) June 2016, pp.53-59.

2. Sadegh vosough, Amir vosough, "PLC and its Applications,"International journal of Multidisciplinary sciences and engineering, Vol. 2, No. 8, Nov. 2011, 2045-7057.

3. Ioannides, M.G., 2004. "Design and implementation of PLC-based monitoring control system for induction motor". IEEE transactions on energy conversion, 19(3), pp.469-476..

4. B. S. Kalaivani, M. Jagadeeswari, "PLC and SCADA Based Effective Boiler Automation System for Thermal Power Plant", International journal of advanced research in computer engineering \& technology, Vol. 4, Issue 4, April 2015, pp. 1653-1657.

5. E. H. Maha M. Lashin, "Different Application of Programmable Logic Controller (PLC)," International Journal of Computer Science and Information Technology, Vol. 4, No. 1, Feb 2014.

6. K. Ali, R. Ghoni, A. N. Abdalla, "Advanced Control of Hybrid-PLC System", International conference on modelling optimization and computing, ISSN 1877-7058, June 2012, pp. 218-225.

7. Endi M, Elhalwagy YZ. "Three-layer PLC/SCADA system architecture in process automation and data monitoring". The 2nd International Conference on Computer and Automation Engineering (ICCAE) 2010 Feb 26,Vol. 2, pp. 774-779.

8. Da'na, S., Sagahyroon, A., Elrayes, A., Al-Ali, A.R. ,Al-Aydi, R., "Development of a monitoring and control platform for PLC-based applications". Computer Standards \& Interfaces, 30(3), pp.157-166.

9. Schneider Electric - "Unity Pro Program Languages and Structure" Reference Manual- 07/2011- 35006144.10.

10. Schneider Electric - "StruxureWare SCADA Expert VijeoCitect v7.40 SP1 User Guide - February 2014 edition for VijeoCitect Version v7.40 SP1. Manual Revision Version v7.40 SP1".

\section{AUTHORS PROFILE}

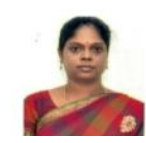

L. Chitra is an Associate Professor and Head in the department of EEE at Aarupadai Veedu Institute of Technology. She received her Bachelor Degree in Electronics and Instrumentation Engineering. She received her Master's Degree in Power Electronics and Drives in Anna University. She completed her PhD in Sathyabama Institute of Science and Technology in the field of Micro Electro Mechanical Systems for sensor design. Her research area includes MEMS, Renewable Energy, Process control, Sensors and Smart Sensors. She has published more than fifteen papers in International Conferences and Journals. She has a teaching experience of more than 18 years. She has received MNRE fund of Rs.1,50,000 for National Conference on Emerging Trends in New Renewable Energy Sources in the year 2014. She has also received a fund of Rs.1,00,000 from Unnat Bharat Abhiyan for Mobile Reverse osmosis based water purification system using Solar PV source for rural India in year 2019. She has also received a fund of Rs.50,000 from Unnat Bharat Abhiyan for DC Micro Grid based Solar PV generation to supply power to street lamp and common utilities in a village.

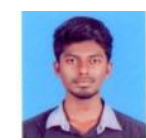

Siranjeevi. S has completed his Bachelor's Degree a Aarupadai Veedu Institute of Technology, Vinayaka Mission's Research Foundation, Chennai. He is one of the notable student in his college, for his interest in the field of PLc and Mechatronics sytems He has worked on many projects related to Renewable Energy, PLC, smart grid, etc., His current research interests include power electronics, renewable energy, Robotics, PLC, etc.

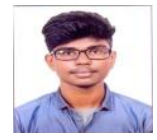

Manikandan.A has completed his Bachelor's Degree a Aarupadai Veedu Institute of Technology, Vinayaka Mission's Research Foundation, Chennai. He has worked on many projects related to Renewable Energy, PLC and its applications, etc.,. He is one of the notable student in his college, for his interest in the field of Automation and Renewable Energy. His current research interests include power electronics, renewable energy, SCADA, PLC, etc.

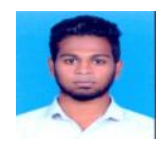

Saravanan. G has completed his Bachelor's Degree at Aarupadai Veedu Institute of Technology, Vinayaka Mission's Research Foundation, Chennai. He is well known student in his college for his excellent Skills in his field of interest. He has worked on many projects related to Mechatronics systems, SCADA, smart grid, etc., His current research interests include Robotics and Automation, renewable energy, PLC, etc. 